\title{
The Molecular Mechanism of Perillaldehyde Inducing Cell Death in Aspergillus flavus by Inhibiting Energy Metabolism Revealed by Transcriptome Sequencing
}

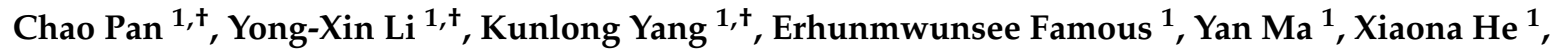 \\ Qingru Geng ${ }^{1}$, Man Liu ${ }^{1, *(1)}$ and Jun Tian ${ }^{1,2, *(1)}$ \\ 1 College of Life Science, Jiangsu Normal University, Xuzhou 221116, China; tchaopan@outlook.com (C.P.); \\ lyxycg@hotmail.com (Y.-X.L.); ykl_long@yeah.net (K.Y.); erhunfamous@yahoo.com (E.F.); \\ yanbtg_ma@163.com (Y.M.); xiaona_he@163.com (X.H.); qingru950504@163.com (Q.G.) \\ 2 Beijing Advanced Innovation Center for Food Nutrition and Human Health, Beijing Technology and \\ Business University, Beijing100048, China \\ * Correspondence: liuman861214@163.com (M.L.); tj-085@163.com (J.T.); Tel.: +86-516-83403172 (J.T.) \\ + These authors contributed equally to this work.
}

Received: 8 February 2020; Accepted: 21 February 2020; Published: 23 February 2020

\begin{abstract}
Perillaldehyde (PAE), an essential oil in Perilla plants, serves as a safe flavor ingredient in foods, and shows an effectively antifungal activity. Reactive oxygen species (ROS) accumulation in Aspergillus flavus plays a critical role in initiating a metacaspase-dependent apoptosis. However, the reason for ROS accumulation in A. flavus is not yet clear. Using transcriptome sequencing of A. flavus treated with different concentrations of PAE, our data showed that the ROS accumulation might have been as a result of an inhibition of energy metabolism with less production of reducing power. By means of GO and KEGG enrichment analysis, we screened four key pathways, which were divided into two distinct groups: a downregulated group that was made up of the glycolysis and pentose phosphate pathway, and an upregulated group that consisted of MAPK signaling pathway and GSH metabolism pathway. The inhibition of dehydrogenase gene expression in two glycometabolism pathways might play a crucial role in antifungal mechanism of PAE. Also, in our present study, we systematically showed a gene interaction network of how genes of four subsets are effected by PAE stress on glycometabolism, oxidant damage repair, and cell cycle control. This research may contribute to explaining an intrinsic antifungal mechanism of PAE against $A$. flavus.
\end{abstract}

Keywords: Aspergillus flavus; Perilla; oxidative stress; energy metabolism; antifungal mechanism

\section{Introduction}

Aspergillus flavus is a deadly saprophytic fungus distributed worldwide, and contaminates many important agricultural crops, such as maize, peanuts, and other crops [1]. Actually, A. flavus is the major producer of aflatoxin, a kind of highly carcinogenic toxins, which poses a dangerous health hazard to human beings and other animals [2]. Unfortunately, in 2004, a severe aflatoxicosis outbreak occurred in Kenya, resulting in 125 deaths because they unintentionally ate aflatoxin-contaminated maize [3]. Besides, A. flavus is also an opportunistic pathogen causing aspergillosis which is very fatal to immunocompromised patients [4]. Therefore, controlling contamination of A. flavus is a critical approach to ensure food safety and human health.

Perillaldehyde (PAE), a natural monocyclic terpenoid in Perilla plants, has a long history of usage as a flavoring ingredient in foods, and these foods seem to be completely safe with little or no health implications [5]. Interestingly, PAE shows an effectively antifungal activity. A volatility test using an air washer demonstrated that PAE displays the highest antifungal activity among five kinds of researched 
essential oils (EOs), of which three EOs belonged to aldehydes and two EOs contained a phenolic hydroxyl group [6]. In 2002, Mcgeady and coworkers found out that PAE had a biological activity of inhibiting the transformation of Candida albicans from a cellular yeast to filamentous and pathogenic cell type [7]. In 2015, we demonstrated that PAE may be used as a potential preservative agent in foods by two decay-inhibiting assays of cherry tomatoes and grapes against $A$. flavus and Aspergillus niger, respectively [8,9]. Besides the morphological evaluation of antifungal activity, an intrinsic antifungal mechanism was illuminated concentrating on a metacaspase-dependent apoptosis triggered by reactive oxygen species (ROS) accumulation induced by PAE [10]. In short, the primary mechanism of antifungal action of PAE has been investigated in previous study.

ROS accumulation triggering oxidant damage seems to be the core of antifungal mechanism of PAE against fungi. Furthermore, the apoptosis process is initiated by ROS through cytochrome $\mathrm{c}$ (Cyt c) catalyzing oxidation of cardiolipin (a polyunsaturated phospholipid in mitochondrial inner membrane), which leads to Cyt c release and apoptosis [11]. To combat oxidative stress, organisms have developed some antioxidant molecules, such as glutathione (GSH) and thioredoxin (Trx) [12]. GSH, the most abundant non-protein thiol, plays an important role in cellular defense against oxidant aggression, providing a protection against ROS damage-induced apoptosis [13]. Both GSH and Trx may be able to protect essential cellular components against oxidative modifications by their conserved cysteine residues drawing electrons from NADPH, eventually [14,15]. As we know, the pentose phosphate pathway (PPP) is a major source of nicotinamide adenine dinucleotide phosphate (NADPH). Besides, under a catalytic action of NADH kinase, NADPH also can be generated by a conversion from NADH, which is mainly produced during glycolysis [16]. Therefore, based on previous literature reviews, researched works and our previous study, we hypothesized that lower NADPH content produced by glycometabolism acts as the ultimate effector leading to A. flavus cell death induced by PAE. To shed more light on the energy-based relationship between antifungal action and A. flavus cell death, transcriptome sequencing of $A$. flavus treated with different concentrations of PAE was carried out. Understanding this antifungal mechanism will greatly help to improve control strategies in food preservation process.

\section{Results}

\subsection{A Preliminary Analysis of Transcriptome Sequencing Data}

To reveal an antifungal molecular mechanism of PAE against $A$. flavus, RNA-seq analysis was carried out. The spores of $A$. flavus were exposed to $0.5 \mu \mathrm{L} / \mathrm{mL}$ PAE, and samples were collected at 2, 4, and $6 \mathrm{~h}$ for transcriptome sequencing. All experiments were performed in triplicate, and samples not treated with oil were used as a control treatment; $45.98 \mathrm{~Gb}$ of clean data of $12 \mathrm{cDNA}$ libraries were obtained, whereas over $3.15 \mathrm{~Gb}$ clean data of each library were gained. Moreover, clean base Q30 and mapped percent of each library were greater than $85 \%$ and $84 \%$, respectively. All preliminary analysis data were shown in Table 1. Therefore, the sequencing data were of high quality, and suitable for further biological analysis.

Table 1. Summary of sequencing data and mapped results in this study.

\begin{tabular}{ccccccc}
\hline Samples & Duplicates & Raw Reads & Clean Reads & Clean Bases/Gb & Q30/\% & Mapped/\% \\
\hline \multirow{2}{*}{ CT } & 1 & $14,463,254$ & $14,010,225$ & $3,528,805,818$ & 88.10 & 86.06 \\
& 2 & $12,973,364$ & $12,519,649$ & $3,153,153,160$ & 87.79 & 85.49 \\
& 3 & $12,891,043$ & $12,502,271$ & $3,148,706,828$ & 88.17 & 86.23 \\
\multirow{2}{*}{ PT2h } & 1 & $16,474,698$ & $14,912,152$ & $3,754,934,036$ & 88.70 & 90.18 \\
& 2 & $15,322,010$ & $13,912,871$ & $3,503,972,558$ & 88.41 & 89.78 \\
& 3 & $16,769,520$ & $15,215,838$ & $3,832,001,194$ & 89.98 & 90.31 \\
\hline
\end{tabular}


Table 1. Cont.

\begin{tabular}{ccccccc}
\hline Samples & Duplicates & Raw Reads & Clean Reads & Clean Bases/Gb & Q30/\% & Mapped/\% \\
\hline \multirow{2}{*}{ PT4h } & 1 & $18,805,595$ & $17,107,102$ & $4,308,390,052$ & 89.92 & 90.27 \\
& 2 & $17,976,647$ & $16,481,808$ & $4,150,736,108$ & 90.18 & 90.55 \\
& 3 & $18,935,548$ & $17,335,243$ & $4,365,533,832$ & 89.94 & 89.73 \\
\multirow{2}{*}{ PT6h } & 1 & $16,979,324$ & $13,183,354$ & $3,319,958,436$ & 85.43 & 84.33 \\
& 2 & $17,624,059$ & $15,768,269$ & $3,971,226,468$ & 90.00 & 89.71 \\
& 3 & $21,925,695$ & $19,631,355$ & $4,942,988,542$ & 89.96 & 89.82 \\
\hline
\end{tabular}

CT: control treatment group; PT2h: PAE treatment group for $2 \mathrm{~h}$; PT4h: PAE treatment group for $4 \mathrm{~h}$; PT6h: PAE treatment group for $6 \mathrm{~h}$.

\subsection{Expression Patterns of DEGs}

According to conventional threshold values of an adjusted $p$-value $<0.01$ and absolute value of $\log _{2}$ FoldChange $\geq 1$, differentially expressed genes (DEGs) between PAE groups and control treatment groups were preliminary screened. To eliminate lower expressed DEGs, the numerous mapped genes were filtered with a strict standard of FPKM $>1$ at each time point after $A$. flavus spores were treated with PAE. Consequently, there were 2798, 2952, and 2954 DEGs filtered at corresponding time point. As for gene expression trends, approximately two-thirds of DEGs were upregulated, and one-third of DEGs was downregulated. Detailed analysis data were shown in Table 2.

Table 2. Variation trend of gene expression quantities of differentially expressed genes (DEGs) in different comparisons.

\begin{tabular}{cccc}
\hline Comparisons & Up & Down & Total \\
\hline PT2h/CT & 1848 & 950 & 2798 \\
PT4h/CT & 1928 & 1024 & 2952 \\
PT6h/CT & 1872 & 1082 & 2954 \\
\hline
\end{tabular}

To screen critical gene sets in response to PAE antifungal stress, a Venn diagram was used to find the common DEGs (cDEGs) in all experimental treatment groups for subsequent analysis. There were 2247 cDEGs, and the number of specific DEGs in each PAE treatment group was increasing with extending treatment duration (shown in Figure 1).

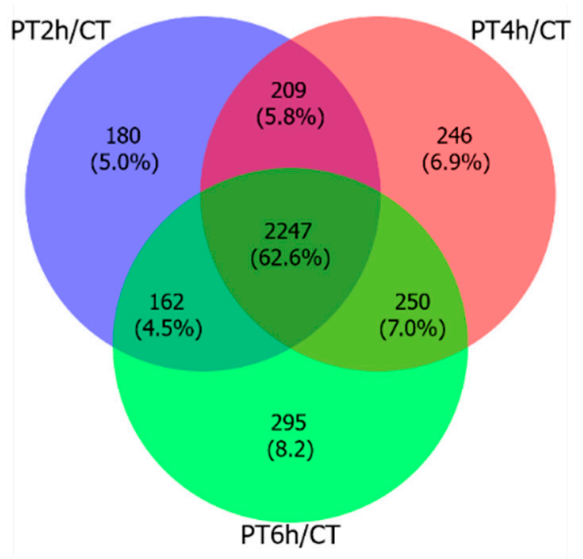

Figure 1. Venn diagram of differentially expressed genes (DEGs). This figure shows the number of common DEGs expressed in each PAE treatment group.

The multidimensional scaling (MDS) plot looks similar to the principal component analysis, and can be used to check the gene expression profile and to evaluate data quality. MDS plot of cDEGs was drawn using FPKM at each experimental time point. As shown in Figure 2, the sequencing data of 
4 and $6 \mathrm{~h}$ PAE groups and control groups exhibited remarkably high stability. However, data of $2 \mathrm{~h}$ PAE groups had a little dispersion, perhaps because PAE treatment time had an impact on a stable and adequate response of spores to PAE treatment. In general, this sequencing data reviewed a good group variation, and were suitable for further biological analysis.

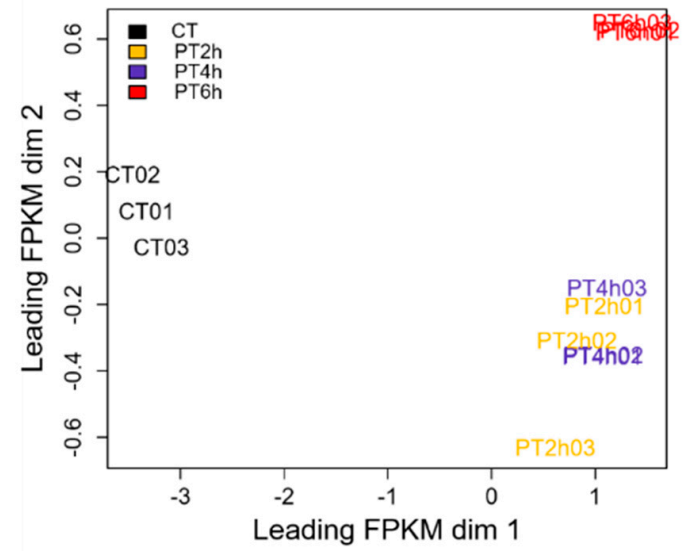

Figure 2. Multidimensional scaling plot of common differentially expressed genes (cDEGs). This figure shows expression pattern of gene set and data quality of cDEGs expressed in each experimental group.

A heat map of FPKM values (Figure 3) showed a marked variation between PAE treatment groups and control groups. Overall, FPKM values of low expressing genes in the control group increased remarkably after PAE treatment at different times, and in contrast, FPKM values of high expressing genes in the control group decreased sharply. This result revealed PAE has a significant effect on transcriptional level of response genes to PAE stress. Specific to PAE treatment groups of A. flavus, variation in the degree of gene expression data become larger and larger corresponding to increased PAE treatment time, according to mapping curve of FPKM values. However, an overall heat map is hard to identify key effective genes inducing $A$. flavus cell death. Therefore, enrichment analysis was carried out in further analyses to find out pivotal pathways associated with antifungal activity of PAE against $A$. flavus.

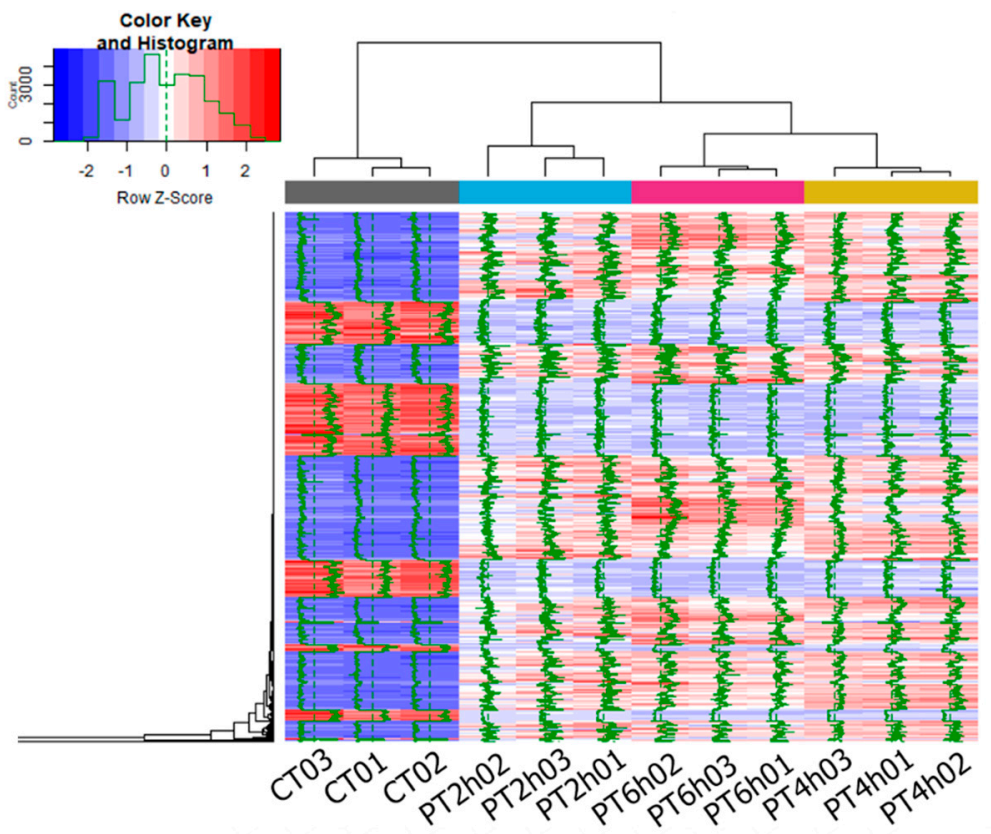

Figure 3. Heat map of DEGs. This figure shows gene expression profiles of common DEGs expressed in each experimental group. 


\subsection{GO Enrichment Analysis of DEGs}

GO enrichment analysis is a powerful method in analyzing gene expression profiles. Thousands of DEGs were enriched in 52 significant terms (adjusted $p$-values $<0.05$ ), of which 49 were biological process terms and three were cellular component terms. The enriched terms were ranked by gene count, and then the top 20 terms were shown on a dot plot in Figure 4. The topmost significantly enriched GO terms in experimental groups were involved in PAE stress response, such as response to stimulus, cellular response to stimulus, response to stress, and cellular response to stress. In addition, some terms associated to DNA damage response also drew our great attention, such as DNA metabolic process, cellular response to DNA damage stimulus, DNA repair, and so on. In accordance with our previous study results, PAE was able to bring about ROS stress and DNA damage [10], resulting in cell death of $A$. flavus. Therefore, the response to stress term, a representative term was given detailed analysis in subsequent text.

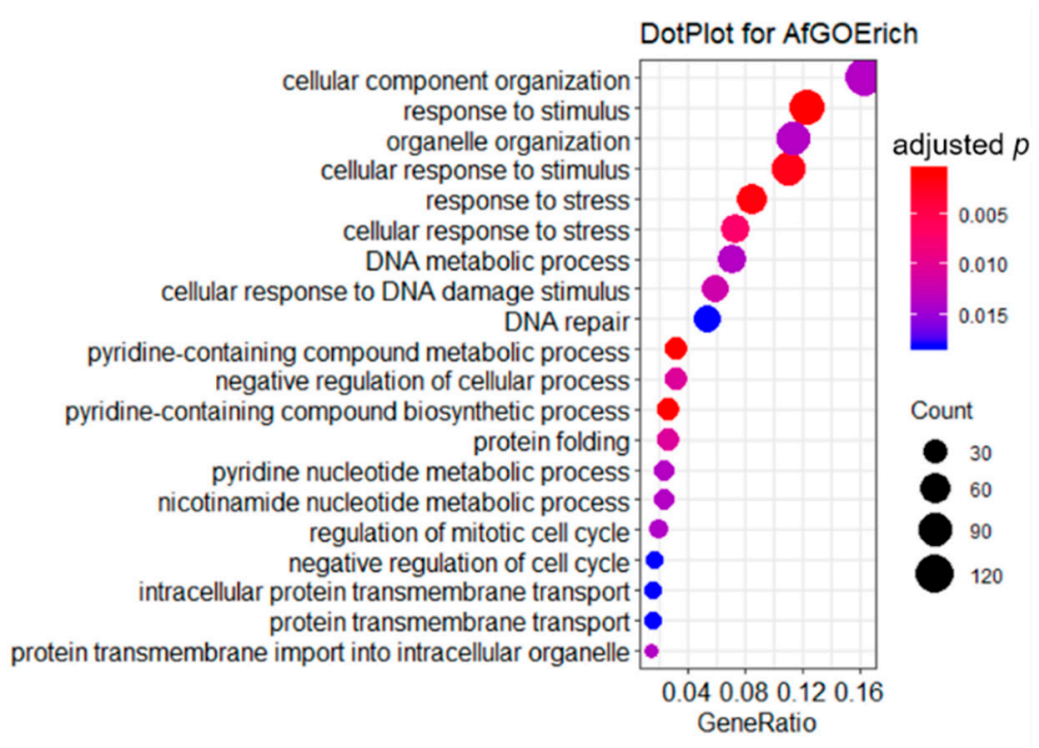

Figure 4. Enriched GO terms of DEGs. This figure shows the top 20 terms of GO enrichment analysis of common DEGs in PAE treatment and control groups.

The term of response to stress was remarkably enriched with an adjusted $p$-value $=1.41 \times 10^{-3}$, and had 64 DEGs. Owing to many genes in this term, a rigid screening criterion of absolute values of $\log _{2}$ FoldChange $>2.5$ was used to screen for pivotal genes associated to stress mechanism induced by PAE. Consequently, 28 DEGs were filtered, and result of data was shown in Figure 5 . On one hand, there were some genes associated to DNA damage response, such as DNA mismatch repair protein, DNA repair protein 1, RNA polymerase II general transcription, and DNA repair factor TFII $\mathrm{H}$, which is in accord with the term results described in above paragraph. On the other hand, many antioxidant genes were also enriched in this term. Remarkably, two genes of catalase were sharply downregulated, indicating scavenging activity of $\mathrm{H}_{2} \mathrm{O}_{2}$ negatively affected by PAE. However, note that two critical antioxidant genes, thioredoxin reductase, and glutathione peroxidase were remarkably upregulated. Thioredoxin reductase belongs to thioredoxin system, and can reduce $\mathrm{H}_{2} \mathrm{O}_{2}$ to water using thioredoxin [17]. Glutathione peroxidase could affect resistance of fungal cells to oxidative stress by accepting GSH, glutaredoxin, and thioredoxin as reducing substrate $[18,19]$. Besides, a gene encoding succinate dehydrogenase assembly factor also was upregulated, helping to produce reducing power (NADH). Therefore, it seems like the antioxidant activity in A. flavus is improved due to PAE treatment. 


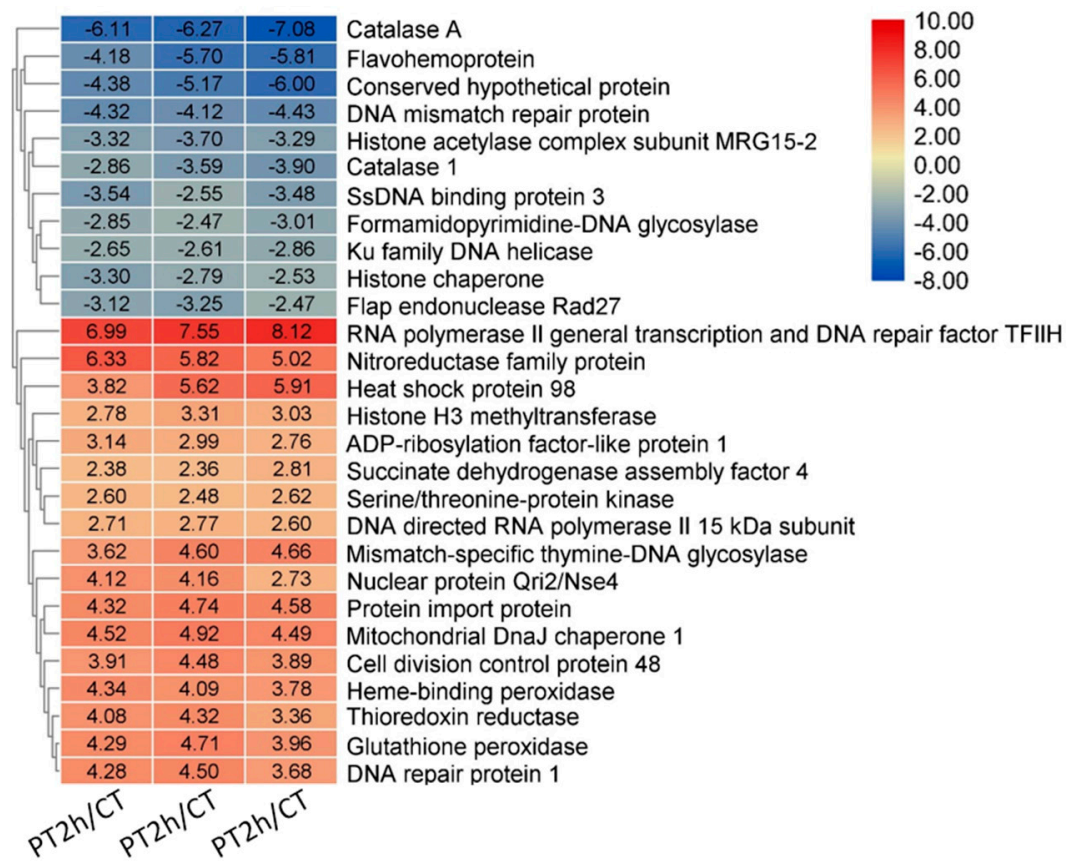

Figure 5. Heat map of differentially expressed genes in the response to stress term in PAE treatment and control groups.

\subsection{KEGG Enrichment Analysis of DEGs}

KEGG is an efficient approach for network prediction of higher-level complexity of cellular processes and organism behavior [20]. Enrichment analysis of KEGG pathway was operated, and enriched terms were ranked by adjusted $p$-values, and closely related 20 terms in response to PAE treatment were shown on a bar plot in Figure 6. Consequently, four antioxidant pathways were screened. To begin with, a pathway of glutathione metabolism was significantly enriched. The pathway included two critical upregulated DEGs, namely glutathione peroxidase and glutathione oxidoreductase showing a direct function against oxidative damage $[18,21]$. Besides, two key glycometabolic pathways were enriched and might indirectly affect oxidative damage of $A$. flavus induced by PAE. Most DEGs belonging to these two pathways were downregulated, implying that reducing equivalent generation was restrained and antioxidant molecules were in an oxidation state with losing protective functions. In lieu of these given reasons, many antioxidant genes were upregulated in GO enrichment analysis as described in above text; $A$. flavus also suffered seriously oxidative damage and apoptosis as proved by our previous study [10]. In addition, the autophagy-yeast pathway was activated in response to energy stress induced by PAE. Finally, MAPK signaling pathway might play an important role in antioxidant response to PAE treatment. 


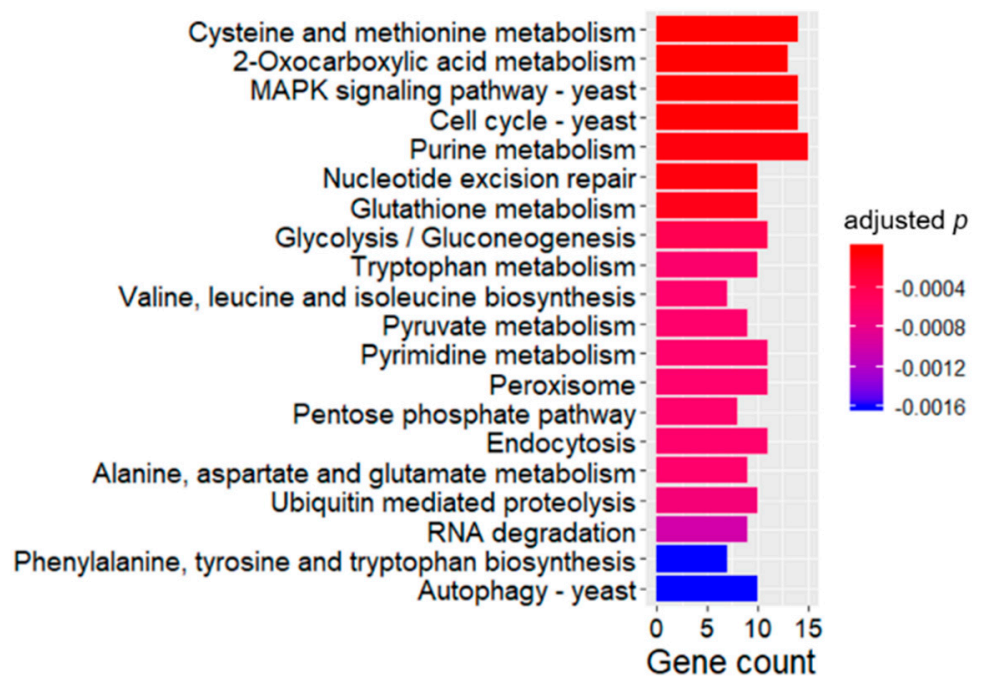

Figure 6. Enriched KEGG pathways of differentially expressed genes (DEGs). This figure shows top 20 pathways of KEGG enrichment analysis of common DEGs in PAE treatment and control groups.

\subsection{A Protein-Protein Interaction Network Analysis of DEGs}

Yap1 may take part in the regulation of response to oxidative stress of $A$. flavus induced by PAE. Yap1 serves as a pivotal transcription factor in response to oxidative stress in fungi, and has an ability to mediated expression of glutathione peroxidase [22] and glutathione oxidoreductase (Glr1) [23] enriched in the glutathione metabolism pathway. Two glycometabolic pathways, namely glycolysis and PPP, involve in production of NADPH: a metabolite required for oxidative stress resistance [15]. The MAPK pathway mediated cellular responses to various stimuli, including ROS [24]. In addition, Skn7 is also a transcriptional regulator that cooperates with Yap1 in response to redox stress signals [25]. Therefore, we hypothesized that Yap1 and Skn7 may play a pivotal role in stress resistance to PAE. Finally, the interactive relationship of 36 genes (Table 3) in GSH metabolism pathway (GshMP) containing both two transcriptional regulators and gene sets of four key pathways filtered through KEGG enrichment analysis above were analyzed by a protein-protein interaction network (Figure 7).

Table 3. Representative DEGs in different comparisons between each PAE treatment and control group.

\begin{tabular}{|c|c|c|c|c|c|}
\hline \multirow{2}{*}{ Pathway } & \multicolumn{3}{|c|}{ PT vs. CT $\log _{2}$ Fold Change } & \multirow{2}{*}{ Name } & \multirow{2}{*}{ Product } \\
\hline & $2 \mathrm{~h}$ & $4 \mathrm{~h}$ & $6 \mathrm{~h}$ & & \\
\hline \multicolumn{6}{|l|}{ Glycolysis } \\
\hline AFLA_073260 & -1.09 & -1.88 & -1.08 & \multirow{4}{*}{ GpdA } & hexokinase \\
\hline AFLA_024480 & -1.49 & -1.76 & -2.75 & & 6-phosphofructokinase alpha subunit \\
\hline AFLA_025100 & -2.45 & -3.28 & -3.76 & & glyceraldehyde 3-phosphate dehydrogenase \\
\hline AFLA_027070 & -2.35 & -2.43 & -2.06 & & acetate-CoA ligase \\
\hline AFLA_037480 & -2.52 & -3.22 & -1.96 & \multirow{3}{*}{$\begin{array}{c}\text { AspF22 } \\
\text { PgkA }\end{array}$} & enolase \\
\hline AFLA_069370 & -1.26 & -1.70 & -1.77 & & phosphoglycerate kinase \\
\hline AFLA_094630 & -1.15 & -1.68 & -1.68 & & triosephosphate isomerase \\
\hline \multicolumn{6}{|l|}{ PPP } \\
\hline AFLA_080390 & -2.12 & -1.96 & -3.27 & \multirow{7}{*}{$\operatorname{PgmA}$} & 6-phosphogluconolactonase \\
\hline AFLA_030710 & -1.65 & -2.02 & -2.65 & & phosphoglucomutase \\
\hline AFLA_015700 & -1.31 & -1.01 & -1.78 & & ribulose-phosphate 3-epimerase \\
\hline AFLA_044820 & -1.83 & -2.13 & -2.10 & & glucose-6-phosphate isomerase \\
\hline AFLA_123760 & 2.84 & 4.39 & 2.76 & & deoxyribose-phosphate aldolase \\
\hline AFLA_125700 & -2.70 & -2.24 & -2.02 & & ribokinase \\
\hline AFLA_128510 & -5.91 & -5.62 & -6.57 & & 6-phosphogluconate dehydrogenase \\
\hline
\end{tabular}


Table 3. Cont

\begin{tabular}{|c|c|c|c|c|c|}
\hline \multirow{2}{*}{ Pathway } & \multicolumn{3}{|c|}{ PT vs. CT $\log _{2}$ Fold Change } & \multirow{2}{*}{ Name } & \multirow{2}{*}{ Product } \\
\hline & $2 \mathrm{~h}$ & $4 \mathrm{~h}$ & $6 \mathrm{~h}$ & & \\
\hline \multicolumn{6}{|c|}{ GSH metabolism } \\
\hline AFLA_076480 & 3.45 & 3.27 & 2.73 & \multirow{3}{*}{ Hyr1 } & glutathione S-transferase \\
\hline AFLA_079910 & 4.29 & 4.71 & 3.96 & & glutathione peroxidase \\
\hline AFLA_082280 & -1.22 & -1.80 & -1.69 & & glutathione S-transferase \\
\hline AFLA_083370 & 2.21 & 2.27 & 2.17 & \multirow[t]{2}{*}{ Glr1 } & glutathione oxidoreductase \\
\hline AFLA_029890 & 3.06 & 3.62 & 3.81 & & glutathione S-transferase \\
\hline AFLA_017920 & -1.75 & -1.55 & -1.82 & \multirow{4}{*}{$R n r-1$} & spermidine synthase \\
\hline AFLA_113250 & 2.43 & 2.98 & 2.44 & & ribonucleotide reductase large subunit \\
\hline AFLA_056570 & 2.75 & 2.61 & 2.44 & & glutathione synthetase \\
\hline AFLA_123650 & -2.95 & -1.12 & -2.95 & & glutathione synthetase \\
\hline \multicolumn{6}{|l|}{ MAPK } \\
\hline AFLA_028230 & -1.82 & -1.18 & -1.60 & NimE & G2/M-specific cyclin \\
\hline AFLA_031340 & 1.98 & 2.27 & 2.01 & AtfA & bZIP transcription factor \\
\hline AFLA_034380 & -2.86 & -3.59 & -3.90 & & catalase \\
\hline AFLA_037000 & -3.04 & -3.9 & -3.88 & Mih1 & cell cycle control protein tyrosine phosphatase \\
\hline AFLA_037350 & 2.05 & 2.07 & 2.31 & & casein kinase I \\
\hline AFLA_039130 & 2.58 & 3.49 & 3.60 & $T c s B / \operatorname{Sln} 1$ & sensor histidine kinase/response regulator \\
\hline AFLA_046760 & 3.27 & 3.54 & 3.55 & $G f d B$ & glycerol 3-phosphate dehydrogenase \\
\hline AFLA_056170 & -6.11 & -6.27 & -7.08 & CatA & spore-specific catalase \\
\hline AFLA_062210 & 1.75 & 1.65 & 1.20 & & response regulator \\
\hline AFLA_068590 & 1.71 & 1.97 & 1.57 & SskB & MAP kinase kinase kinase \\
\hline AFLA_090910 & 2.81 & 3.61 & 3.57 & Mcm1 & MADS box transcription factor \\
\hline AFLA_129340 & 2.65 & 2.95 & 3.01 & Yap1 & AP-1-like transcription factor \\
\hline AFLA_034540 & 2.34 & 2.11 & 1.99 & Skn7 & stress response transcription factor \\
\hline
\end{tabular}

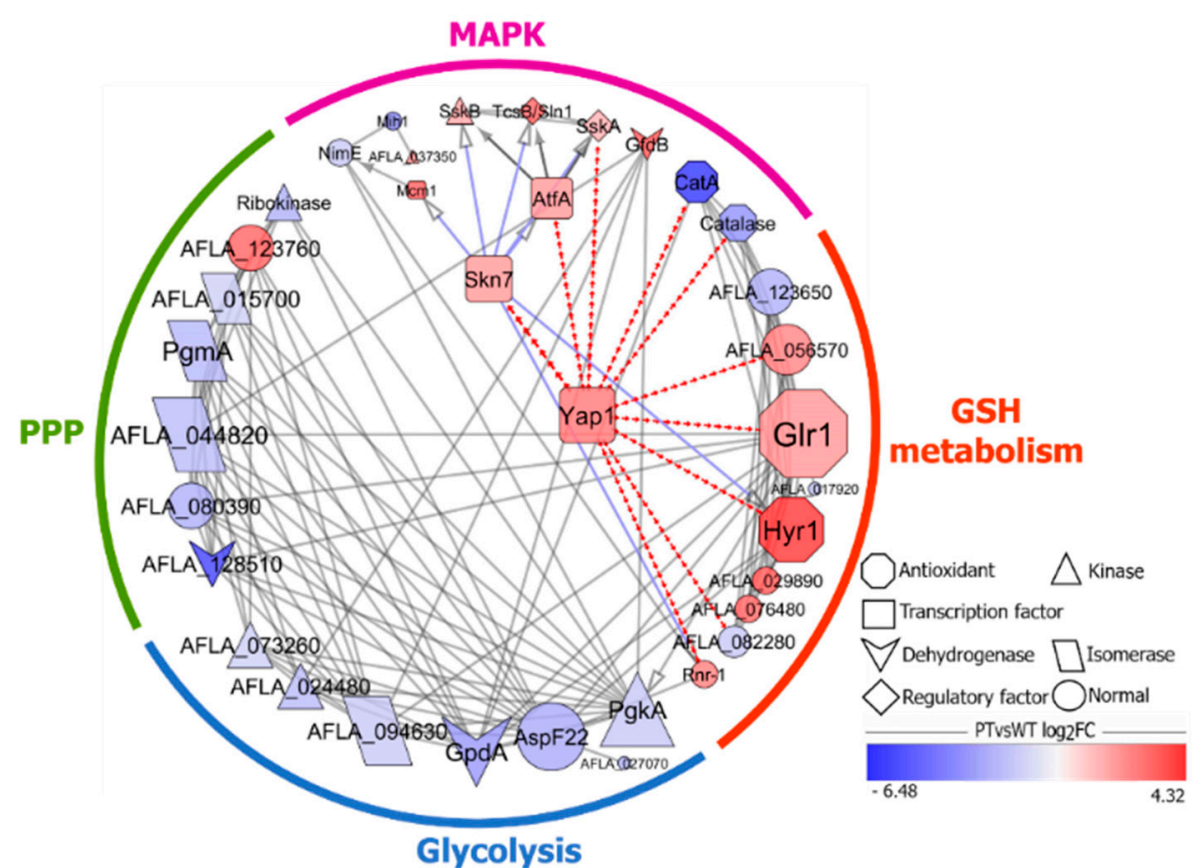

Figure 7. Protein-protein interaction network of differentially expressed genes. The icon size is proportional to the number of protein-protein interactions. Red fill color stands for positive regulation of proteins encoded by corresponding genes, and blue fill color for negative regulation of proteins. 
The interaction relationship of gene sets enriched in four key pathways was revealed in Figure 7 in details. In general, DEGs in four pathways were divided into two groups: one downregulated group included glycolysis and PPP pathway, and another upregulated group consisted of MAPK signaling pathway and GshMP.

First, two critical genes, AFLA_073260 and AFLA_024480, encoding hexokinase and 6-phosphofructokinase, respectively, were remarkably downregulated in glycolysis pathway, and so conversion of glucose to fructose 1,6-bisphosphate was suppressed [26]. Moreover, triosephosphate isomerase encoded by AFLA_094630 helped to generate glyceraldehyde-3-phosphate, which was conversed to 1,3-diphosphoglyceric acid by glyceraldehyde 3-phosphate dehydrogenase GpdA encoded by AFLA_025100 coupled with NADH production. Besides, enolase AspF22 encoded by AFLA_037480 catalyzed the generation of phosphoenolpyruvic acid, a critical substrate for ATP production. In short, given the genes above being all downregulated, therefore, the glycolysis process was roundly inhibited by PAE from glucose activation to reducing power (NADH) and energy (ATP) generation.

Secondly, the PPP was severely restrained by PAE. Initially, there was a rising trend of transcriptional regulation of glucose 6-phosphate, a primary substrate for PPP [27]. An accumulation of glucose-6-phosphate in glycolysis was induced by downregulation of glucose-6-phosphate isomerase encoded by AFLA_044820 coupled with a conversion inhibition of glucose 6-phosphate to fructose 6-phosphate, and of phosphoglucomutase PgmA encoded by AFLA_030710 inhibiting a conversion of glucose-6-phosphate to glucose-1-phosphate in gluconeogenesis. Thus, it seemed like the PPP acts as a key effector in response to the stress caused by PAE. Moreover, a following critical metabolic step of NADPH production in PPP was blocked by two sharply downregulated genes. In detail, 6-phosphogluconolactonase encoded by AFLA_080390 catalyzed the formation of 6-phosphogluconic acid, which afterwards was dehydrogenized under a catalytic action of 6-phosphogluconate dehydrogenase encoded by AFLA_128510, coupled with producing numerous NADPH. In summary, it is likely that PPP is inhibited by PAE especially in the step of NADPH generation.

By contrast to the two downregulated glycometabolism pathways described above, transcriptional level of DEGs in GshMP was increased in an overall gene expression profile in response to PAE stress. It seemed like the negative expression of a glutathione synthetase encoded by AFLA_123650 acts as a key player resulting in a direct decrease of GSH level. According to our data, glutathione peroxidase Hyr1 encoded by AFLA_079910 was a dramatically upregulated antioxidant enzyme, of which expression was specifically induced in presence of Yap1 [22]. Besides, upregulated glutathione oxidoreductase Glr1 encoded by AFLA_083370 could regenerate the reduced glutathione playing a critical role in cellular defense against oxidative damage [21], and it was also a target gene for Yap1 transcriptional regulation [23]. Moreover, glutathione S-transferase involves in resistance against oxidative stress [28], and two genes encoding glutathione S-transferase were sharply upregulated with a $\log _{2}$ FoldChange value greater than 3. Finally, ribonucleotide reductase large subunit Rnr1 encoded by AFLA_113250 was positively expressed in response to DNA damage [29]. Obviously, the antioxidant function of GshMP was enhanced. Perhaps, the decrease of reducing power content caused in glycolysis and PPP described above was the initial reason why an oxidative damage took place in A. flavus under PAE stress.

Autophagy serves as a survival strategy through cellular self-digestion in response to nutrient starvation, ubiquitously occurring in plant, animal, and fungal cells [30]. Severe inhibition of glucose metabolism was described above, and some DEGs were enriched in Autophagy pathway. Atg17 is a critical gene involving in autophagosome formation [31], and our data showed that this gene encoded by AFLA_138020 was upregulated. Moreover, serine palmitoyltransferase 2 acts as apoptosis-inducing gene [32], and was also upregulated. Actually, autophagy can act as an approach to cell death through activating apoptosis pathway [33]. Together with our previous results that PAE can induce an apoptosis in A. flavus [10], autophagy may play a critical role in response to PAE stress.

As for MAPK pathway, functions of enriched DEGs were divided into three modules associated to various biological processes. The first functional gene group consisted of two downregulated 
$\mathrm{H}_{2} \mathrm{O}_{2}$-scavenging genes, namely, catalase and spore-specific catalase CatA, encoded by AFLA_034380 and AFLA_056170, respectively. The second group of DEGs involved in osmotic stress response, and all genes were upregulated. Glycerol 3-phosphate dehydrogenase GfdB encoded by AFLA_046760 was a $\mathrm{NADP}^{+}$-dependent glycerol dehydrogenase, and can respond to hyperosmotic shock in Aspergillus [34]. Besides, SskA encoded by AFLA_062210 [35] was a response regulator to adapt to osmotic stress [36], and was regulated by AtfA [35], a bZIP transcription factor encoded by AFLA_031340 regulating oxidative and osmotic stress responses in Aspergillus [37]. In HOG pathway, TcsB/Sln1 encoded by AFLA_039130 was a sensor histidine kinase/response regulator, and regulated the downstream gene expression of SskB a MAP kinase kinase kinase [38], which responded to osmotic shock [39]. Interestingly, the third gene set participated in cell cycle control. There were two downregulated genes associated to cell cycle control, namely, a G2/M-specific cyclin NimE and a cell cycle control protein tyrosine phosphatase Mih1. In fact, these two genes above were regulated by Mcm1, a MADS box transcription factor encoded by AFLA_090910 related with regulation of M/G1 phase of the cell cycle [40] and were regulated by the transcriptional regulator Skn7, also having a cell cycle-related role [41]. The gene expression profile of MAPK pathway showed a specific mechanism of A. flavus in which antioxidant activity became weak, cell cycle was stocked, and resistance to osmotic shock was improved.

\subsection{Confirmation of DEGs by RT-qPCR}

To validate RNA-seq expression estimates, relative expression quantity of nine pivotal DEGs in four pathways described above were measured by RT-qPCR (Figure 8). According to present research, ROS accumulation is critical initiation of antifungal action of PAE [10]. In this research, RNA-seq data implied that inhibition of reducing power generation plays an ultimate role in bringing about oxidation damage of $A$. flavus. Therefore, first, we verified consistency of relative expression quantity of all dehydrogenase genes described in the protein-protein interaction network above, including GpdA of glycolysis pathway, 6-phosphogluconate dehydrogenase encoded by AFLA_128510 of PPP pathway, and GfdB of MAPK pathway. Particularly, the downregulated expression of two dehydrogenase genes of GpdA and AFLA_128510 led to an inhibition of reducing power generation. Second, two oxidative damage repair genes of Hyr1 and Glr1 of GshMP were upregulated, in accord with results of RT-qPCR assays. In addition, the upregulated expression of two transcription factors, also two antioxidant genes of Yap1 and $s k n 7$ were verified by RT-qPCR. These results highlighted the fact that activity of oxidative damage repair in A. flavus is enhanced by PAE stress. Besides, a result of RT-qPCR showed that expression of NimE associated to cell cycle control from MAPK pathway was restrained. Therefore, the results of RT-qPCR confirmed the reliability of RNA-seq data and our hypothetical antifungal mechanism. 

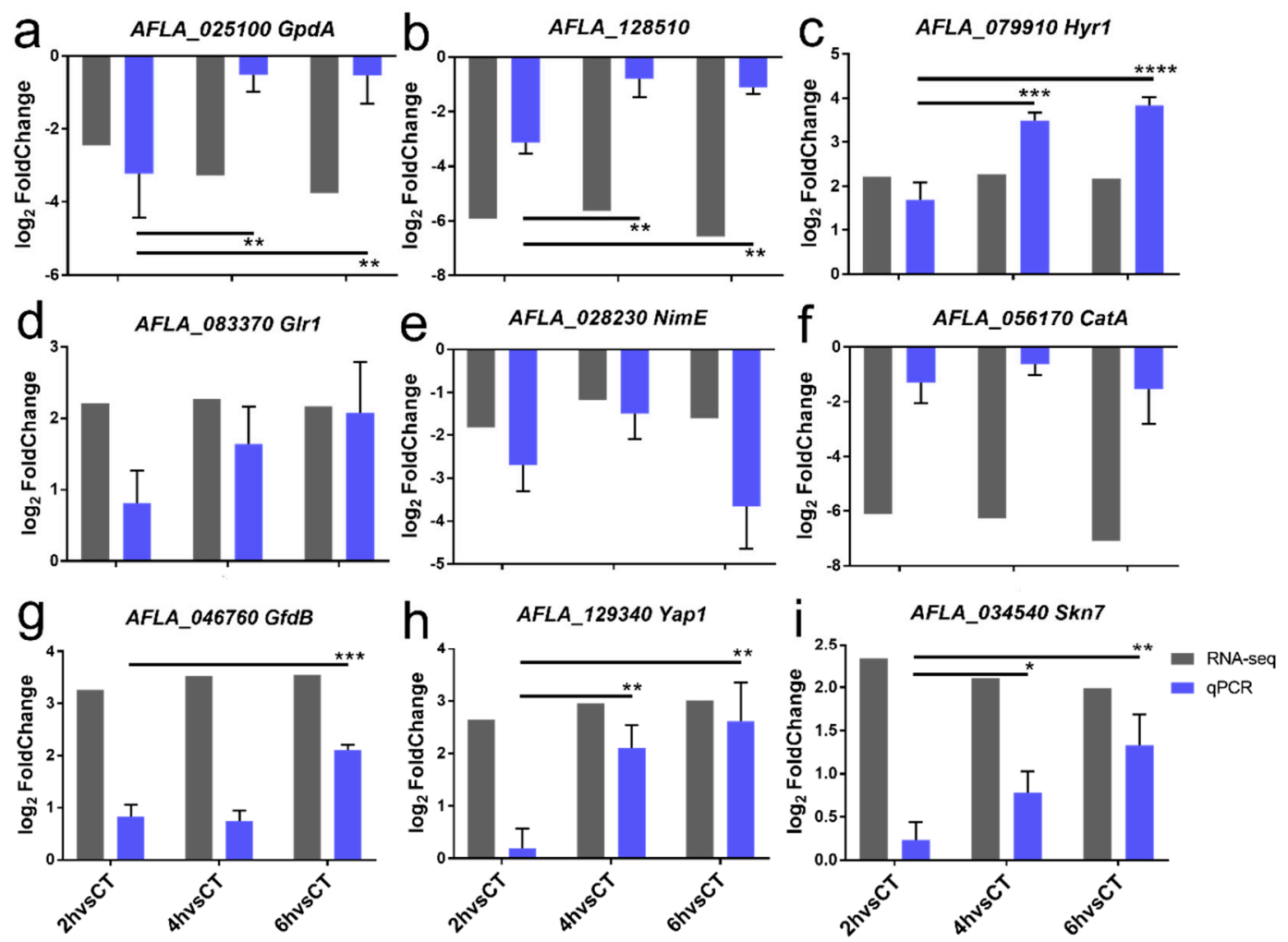

Figure 8. Validation of relative expression levels of critical differentially expressed genes in transcriptome data by RT-qPCR. (a) Glycolysis pathway, (b) 6-phosphogluconate dehydrogenase encoded by AFLA_128510 of PPP pathway, (c,d) GSH metabolism pathway, (e-g) MAPK pathway, and (h,i) two transcription factors. Relative expression level of DEGs was showed using an index of $\log _{2}$ FoldChange, which was calculated as a ratio of a gene expression level in PAE treatment and control group. Data are means \pm standard deviation of three replicates. ${ }^{*} p<0.05 ;{ }^{* *} p<0.01 ;{ }^{* * *} p<0.001$; ${ }^{* * * *} p<0.0001$.

\section{Discussion}

PAE seems to be a very attractive antifungal agent used for food storage. For a very long time now, PAE has been generally regarded as a safe flavoring ingredient for foods [5], and it has some hygienic functions, such as hypolipidemic action [42], protection against inflammation [43,44], and assisting in curing depression [45]. Besides, in our previous study, PAE showed an effective antifungal activity against some food-borne fungi, such as A. falvus [10], A. niger [9], and Ceratocystis fimbriata [46], with a striking inhibition of food decay, and against Candida albicans, which protects humans from candidiasis infection [44,47]. Moreover, the antifungal pathways of PAE must be partly explained. PAE, as a kind of EOs, may readily dissolve in biological membranes [48], and leads to a serious injury to plasma membrane through indirect interference in ergosterol biosynthesis [49], resulting in release of cytoplasmic contents into extracellular space. In fact, mitochondria is an important organelle consisting of phospholipid bilayers, and thus PAE can disturb its function, leading to abnormalities of the electron transport chain (ETC), resulting in producing numerous ROS [10]. Cyt c plays a critical role in cardiolipin oxidation, and then assists to release the proapoptotic Cyt c to cytoplasm [11]. Afterwards, metacaspases, orthologues of the caspase family in mammalian cells, are activated by proapoptotic Cyt c, and give rise to the cell death with apoptotic-like characteristics, such as phosphatidylserine exposure and DNA fragmentation in A. falvus [10]. In general, a metacaspase-dependent pathway seems to be a critical mechanism that PAE uses to induce $A$. falvus cell death.

The antifungal pathways associated to direct apoptotic processes have been revealed clearly; however, there is very little published research papers about the regulatory network of overall antifungal pathways based on a whole genome sequence data. To thoroughly address the antifungal 
mechanism, we used transcriptomics technologies to gain further insights into potential links between other biological processes and these antifungal pathways induced by PAE in A. flavus. In this assay, spores of A. flavus were treated by different concentration of PAE solutions. DEGs were judged by a comparison of RNA-seq data between experimental groups and control group. Afterwards, pathway enrichment analysis of GO and KEGG was used to analyze gene expression profiles of DEGs. Consequently, most of the topmost significantly enriched GO terms were found to be involved in stress response and DNA damage response, coinciding with our previous study results that PAE brought about ROS stress and DNA damage in A. flavus [10]. Intriguingly, KEGG enrichment analysis filtered four pathways in response to oxidant damage, namely, GSH metabolism, PPP, and glucolysis pathway, as well as MAPK signaling pathway. Therefore, we proposed that the antifungal mechanism of PAE is a complex regulatory network whereby metabolic inhibition of glucolysis and PPP plays an initial role in holding back generation of reducing power, which indirectly contributes to oxidant damage and subsequently apoptosis in A. flavus.

ROS contains superoxide anion $\left(\mathrm{O}_{2}^{-}\right)$, hydrogen peroxide $\left(\mathrm{H}_{2} \mathrm{O}_{2}\right)$, and hydroxyl radical (HO.) et al. [50]. Numerous ROS may increase in response to external stimulus of Eos [51]. $\mathrm{O}_{2}{ }^{-}$is generated by one-electron reduction of molecular oxygen $\left(\mathrm{O}_{2}\right)$ through cytosolic NADPH oxidases (NOXs) or in mitochondrial ETC complexes [52]. However, the gene encoding NOXs in A. flavus showed a low-level expression with FPKM $<1$, and so it was likely that NOXs do not participate in regulation of cell death induced by PAE. Consequently, ETC seemed to be the primary source of ROS production [51]. In matrix, $\mathrm{O}_{2}^{-}$is rapidly converted to $\mathrm{H}_{2} \mathrm{O}_{2}$ by superoxide dismutase (SOD) [52] and $\mathrm{HO}$ - is produced from $\mathrm{H}_{2} \mathrm{O}_{2}$ by Fenton reaction [53]. Given strong oxidizing potential, $\mathrm{HO}$ - may cause severe oxidative damage to cellular macromolecules, such as lipids, proteins and so on [54]. To combat oxidative stress, fungi have developed effective antioxidant systems consisting of GSH, glutathione and thioredoxin pathways [55]. Cysteine serves as a key residue in enzyme catalysis and protein fold et al., and is however easily oxidized by ROS, leading to unwanted modifications of proteins [56]. GSH abundant in matrix may reduce oxidized cysteine residues, and protects proteins from irreversible oxidation [21]. The oxidized GSH (GSSG) is recycled to reduction state by NADPH-dependent glutathione reductase (GR) [57]. Moreover, oxidized glutaredoxin is reduced by GSH [55], and formation of reduced thioredoxin is catalyzed by NADPH-dependent thioredoxin reductase [57]. Therefore, it is tempting to speculate that NADPH produced in PPP serves as the initial electron donor for antioxidant protection of fungi against EOs.

GSH metabolism may play a key role in response to PAE stress. In our previous assays, accumulation of ROS induced by PAE played a vital role in initiating an apoptosis process, coupled with large-scale DNA fragmentation that occurred in nuclear [10]. In line with this, using GO enrichment analysis, we screened many terms related to DNA damage response. Furthermore, we particularly revealed an insightful network of PAE antifungal pathways through KEGG enrichment analysis. First, due to the phenomenon of ROS accumulation, we energetically focused on the analysis of antioxidant pathways, especially GshMP. Unexpectedly, no inhibition effects emerging from GSH metabolism were responsible for PAE treatment, coupled with many upregulated antioxidant genes. In details, Glr1 glutathione oxidoreductase assists to regenerate GSH, and then Hyr1 glutathione peroxidase serves as a cofactor of the reduction reaction of oxidatively modified lipids and proteins, as well as glutathione S-transferase contributing to catalyzing a GSH-dependent reduction of organic hydroperoxides [58]. Besides, Rnr1, one of the major subunits of ribonucleotide reductase can protect cell against DNA damage by its repair function [59]. Except for these genes, Yap1, an overall regulator notably took part in the regulation of antioxidant processes with a large $\log _{2}$ FoldChange value. Apparently, GshMP serves as an antidrug resistance agent in A. flavus to PAE.

To further explore the causal relationship between A. flavus spore apoptosis and PAE stress, pathways generating reducing power were analyzed. Initially, we analyzed the regulation of genes in glycolysis. First of all, phosphorylation of glucose is catalyzed by hexokinases [60], and then 6-phosphofructokinase catalyzes a reversible generation of fructose 1,6-bisphosphate using fructose 
6-phosphate [61]. The two genes above were downregulated in sequencing data. Afterwards, in the downstream pathway, the level of glyceraldehyde-3-phosphate decreased under the catalytic action of downregulated triosephosphate isomerase. During the following reaction process, an inhibition of NADH production occurred due to the lower-level reaction substrate glyceraldehyde-3-phosphate and negative regulation of catalyzing enzyme glyceraldehyde 3-phosphate dehydrogenase. Actually, NADPH serves as a key force needed for oxidative stress protection [62], of whose formation can be catalyzed by NADH kinase [16], and eventually, the antioxidant activity in A. favus decreases coupled with the low level of NADPH content. Moreover, the generation of another critical product ATP of glycolysis tended to be restrained due to downregulated expression of Enolase. Therefore, glycolysis process was nearly collapsed by PAE. On the other hand, PPP, a major source of reducing power NADPH [27] seemed to be also severely restrained by PAE. In the first place, 6-phosphogluconolactonase catalyzes the generation of 6-phosphogluconic acid, which is subsequently dehydrogenized under the catalytic action of 6-phosphogluconate dehydrogenase, coupled with numerous NADPH production. According to our data, the two genes described above were downregulated, indicating a committed generation step of NADPH was blocked. Therefore, the role played by NADPH in protection from oxidative stress [62] was suppressed. In conclusion, perhaps the inhibition of NADPH generation in glycometabolism plays a fateful role in triggering A. flavus spore apoptosis by PAE.

Besides, the MAPK pathway also played an important role in inducing A. flavus spore death by PAE. As we know, catalase is important in the detoxification of $\mathrm{H}_{2} \mathrm{O}_{2}$ [63], and so negative expression of two catalases in MAPK pathway revealed that $A$. flavus spores tend to suffer serious oxidant damage, especially under the condition of reducing power deprivation. On the other hand, there is an independent branch associated to cell cycle inhibition. Mih1 is a tyrosine phosphatase and can promote entry into mitosis by modification of dephosphorylation reactions [64]. NimE serves as a G2/M-specific cyclin [65]. The genes encoding the two important proteins above were all down regulated, indicating an inhibition action occurred in A. flavus spores. Except for the regulations of suppressing $\mathrm{H}_{2} \mathrm{O}_{2}$ elimination and cell proliferation, an osmotic response pathway was activated remarkably. First, GfdB is a NADP ${ }^{+}$-dependent glycerol dehydrogenase in Aspergillus in response to hyperosmotic shock [34]. Second, SskA acts as a response regulator related to osmotic stress [36], of which action is regulated by AtfA [35], a bZIP transcription factor regulating oxidative and osmotic stress responses in Aspergillus [37]. Besides, TcsB/Sln1 serves as a sensor histidine kinase/response regulator, and regulates the downstream gene expression of a MAP kinase kinase kinase SskB [38] in response to osmotic shock [39]. Surprisingly, ROS accumulation led to a noteworthy increase of osmotic response. Actually, this above relationship agreed with the research of Riddhiman and coworkers that yeast can adapt to a stressful environment by cross-protection, where oxidative stress protects against osmotic stress but not vice versa [66]. Therefore, MAPK pathway serves as an effector in inducing oxidant damage and cell cycle arrest.

\section{Materials and Methods}

\subsection{Chemical and Fungus Strain}

The PAE (CAS Registry No. 18031-40-8) used in this study was purchased from Tokyo Chemical Industry Co. Ltd. PAE was dissolved in $1 \%(v / v)$ Tween- 80 with ultrasonic wave, prepared as a mother liquor in a concentration of $5.0 \mu \mathrm{l} / \mathrm{mL}$. A. flavus (NRRL 3357) was purchased from the China General Microbiological Culture Collection Center (CGMCC). The A. flavus was cultured for 4 days at $28^{\circ} \mathrm{C}$ in potato dextrose agar medium (PDA, $20 \%$ potato, $2 \%$ dextrose, $1.5 \%$ agar) and stored in a refrigerator at $4{ }^{\circ} \mathrm{C}$.

\subsection{PAE Treatment and Sample Collection}

The A. flavus spore suspension in $0.1 \%(v / v)$ Tween- 80 was adjusted to $5 \times 10^{7}$ spores $/ \mathrm{mL}$ using a hemocytometer. Spore suspension and phosphate-buffered solution containing $2 \%$ glucose (PBS- $2 \% \mathrm{G}$ ) 
were equivolumetrically mixed, incubated at $28^{\circ} \mathrm{C}$ and $200 \mathrm{rpm}$ for $4 \mathrm{~h}$ to obtain activated spores of A. flavus. After that, both $100 \mu \mathrm{L}$ PAE mother liquor and $900 \mu \mathrm{L}$ spore suspension were mixed to a final PAE concentration of $0.5 \mu \mathrm{L} / \mathrm{mL}$. The spore suspension was cultured at $28^{\circ} \mathrm{C}$ and $200 \mathrm{rpm}$. At treatment points of 2, 4, and $6 \mathrm{~h}$, the fungal spores were harvested at $7000 \mathrm{~g}$ for $5 \mathrm{~min}$ and washed three times with PBS. All experiments were carried out in 3 independent biological replicates, and samples that were not treated with oil were used as a control treatment.

\subsection{RNA Isolation, Library Construction, and Sequencing}

RNA extraction was performed using Trizol (Invitrogen, Carlsbad, California, USA) according to the manufacturer's instruction. RNA purity and concentration were assessed by Thermo Scientific NanoDrop 2000c, and RNA integrity was assessed with the Bioanalyzer 2100 RNA 6000 Nano Kit from Agilent Technologies. High-quality RNA was used in library construction. Sequencing libraries were generated using a NEBNext Ultra RNA library prep kit for Illumina (New England Biolabs, Ipswich, MA, USA) following the manufacturer's instruction. In brief, mRNA was enriched from total RNA using NEBNext Oligo $d(T)_{25}$ magnetic beads, and then the purified mRNA was randomly fragmented by addition of fragmentation buffer. Afterwards, first-strand cDNA was synthesized using a random hexamer primer and ProtoScript II Reverse Transcriptase on mRNA template. Subsequently, second-strand cDNA synthesis was performed using RNase $\mathrm{H}$ and DNA polymerase I, and then the double-stranded cDNA was purified using 1.8 X Agencourt AMPure XP Beads. The cDNA library was performed by End Repair/dA-tail, and immediately proceeded to adaptor ligation in preparation for hybridization, and then the ligation reaction was purified using AMPure XP Beads in order to obtain larger 200 nt size of fragments. After that, the cDNA library was enriched by PCR using NEBNext high-fidelity DNA polymerase, universal PCR primers and index $(X)$ primer, and was purified using Agencourt AMPure XP Beads. Finally, the library quality was assessed using an Agilent Bioanalyzer 2100 system. Libraries were sequenced on an Illumina Hiseq X Ten platform.

\subsection{Data Analysis}

Raw reads were detected using a sequencing-by-synthesis technology, and they were stored in FASTQ format. Clean reads for downstream analysis were obtained by removing adapters and poor quality reads. Afterwards, the Q30 and GC contents of clean data were calculated. Clean reads were mapped to a reference genome of A. flavus NRRL3357 (assembly JCVI-afl1-v2.0) using TopHat2 software [67], and the number of reads mapped to each gene was counted. To measure the quantitative relation between mapped read counts and their real expression level, Cufflinks software was used to calculate for Fragments Per Kilobase of transcript per Million fragments mapped (FPKM) of each clean read based on mapped read counts and transcript length [68].

\subsection{Differential Expression Analysis}

Differentially expressed genes (DEGs) were screened by a comparison of PAE treatment groups with control groups and then analyzed with DESeq package using RStudio software (version 1.2.1335; RStudio, Inc.). To control false positive results in hypothesis test, the $p$-value was adjusted using the Benjamini-Hochberg approach to calculate the false discovery rate (FDR). DEGs were identified based on an adjusted $p$ value $<0.01$ and absolute value of $\log _{2}$ FoldChange $\geq 1$. Moreover, to eliminate lower expressed DEGs, the numerous counts were screened with a stricter criterion of FPKM $>1$ at each time-point after $A$. flavus spores were treated with PAE.

Expression patterns of DEGs were analyzed by Venn diagram, multidimensional scaling (MDS) plot, and heat map. First, differential expression numbers of DEGs at different PAE treating time points were showed by Venn diagram using VennDiagram package with RStudio, and then the common DEGs at each time-point were selected for subsequent analysis. Moreover, a MDS plot and a heat map of DEGs' FPKM were drawn using limma package [69] and plots package [70] within RStudio, respectively. 
Gene Ontology (GO) annotation and enrichment of DEGs were performed using clusterProfiler package using RStudio software [71]. The GO annotation file of A. flavus was retrieved with AnnotationHub package within RStudio. For functional enrichment analysis of DEGs, categories with an adjusted $p$ value $<0.05$ were counted as enriched term in GO term enrichment.

Kyoto Encyclopedia of Genes and Genomes (KEGG) enrichment and protein-protein interaction analysis were calculated by STRING v11 [72]. The gene list of DEGs was written in an analysis interface of multiple proteins, and then searched following the website instruction. KEGG pathways were enriched using the Analysis function, and only the pathways with $F D R<0.05$ were counted as significantly enriched. On the other hand, protein-protein interaction data were outputted using the Exports function to a TSV file. Subsequently, the TSV file was imputed into Cytoscape (version 3.6.3), and then an aesthetic protein-protein interaction network was drawn.

\subsection{Validation of DEGs by RT-qPCR}

To confirm the reliability of RNA-seq data, relative expression quantity of 9 key DEGs in different pathways were measured by real-time qPCR (RT-qPCR). PCR primers were designed using Primer Premier 6 software (Premier Biosoft International, USA). The $\beta$-tubulin gene was used as an internal control for normalization of gene expression [73]. First-strand cDNAs were synthesized using a RevertAid First Strand cDNA Synthesis Kit (Thermo Scientific, Waltham, MA, USA). RT-qPCR was performed using a $2 \times$ Plus SYBR real-time PCR mixture Kit (BioTeke, Beijing, China) on an Applied Biosystems StepOnePlus ${ }^{\mathrm{TM}}$ Real-Time PCR system (Applied Biosystems, Foster, CA, USA). Each RT-qPCR mixture contained $1 \mu \mathrm{L}$ template, $0.5 \mu \mathrm{L}$ forward primer and $0.5 \mu \mathrm{L}$ reverse primer,

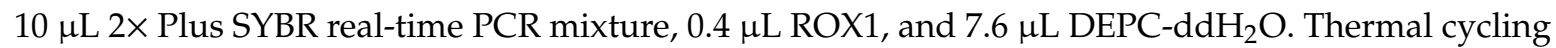
parameters for RT-qPCR were as follows; $94{ }^{\circ} \mathrm{C}$ for $2 \mathrm{~min}, 40$ cycles of $94{ }^{\circ} \mathrm{C}$ for $15 \mathrm{~s}, 60^{\circ} \mathrm{C}$ for $30 \mathrm{~s}$. Relative expression level was calculated using the $2^{-\Delta \Delta C t}$ method [74].

\subsection{Statistical Analysis}

The statistical significance of data from different PAE treatment groups was calculated by one-way ANOVA with Duncan multiple range tests using SPSS 21.0 software (IBM-SPSS Inc., USA). ${ }^{*} p<0.05$; ${ }^{* *} p<0.01 ; * * * 0<0.001 ; * * * * 0<0.0001$.

\section{Conclusions}

In conclusion, results of this study show a molecular regulation mechanism of PAE inducing cell death of A. flavus by primarily inhibiting energy metabolism (Figure 9). PAE exposure gives rise to an accumulation of ROS [10], which triggers an increase of antioxidant activity by activating GshMP and antioxidant transcription factor Yap1, to combat the oxidative damage. On the other hand, however, glucolysis and PPP are remarkably inhibited by PAE, coupled with a downregulated expression of key dehydrogenase genes, resulting in a less production of reducing power, which further inhibits the regeneration of GSH and sharply weaken the ability of preventing oxidative damage in A. flavus cells. Besides, MAPK pathway is also regulated by PAE via the negative expression of catalase Cat $A$, with a result of a block of ROS scavenging, and a contribution to ROS accumulation, strengthening the oxidative damage. In the end, PAE induces superfluous ROS, initiates a metacaspase-dependent apoptosis pathway, and at last results in cell death of A. flavus. To thoroughly illuminate the antifungal mechanism of PAE mediated by inhibition of reducing power production, further researches need to pay more attention to specific regulation mechanism of glycometabolism pathways in A. flavus after PAE treatment. 


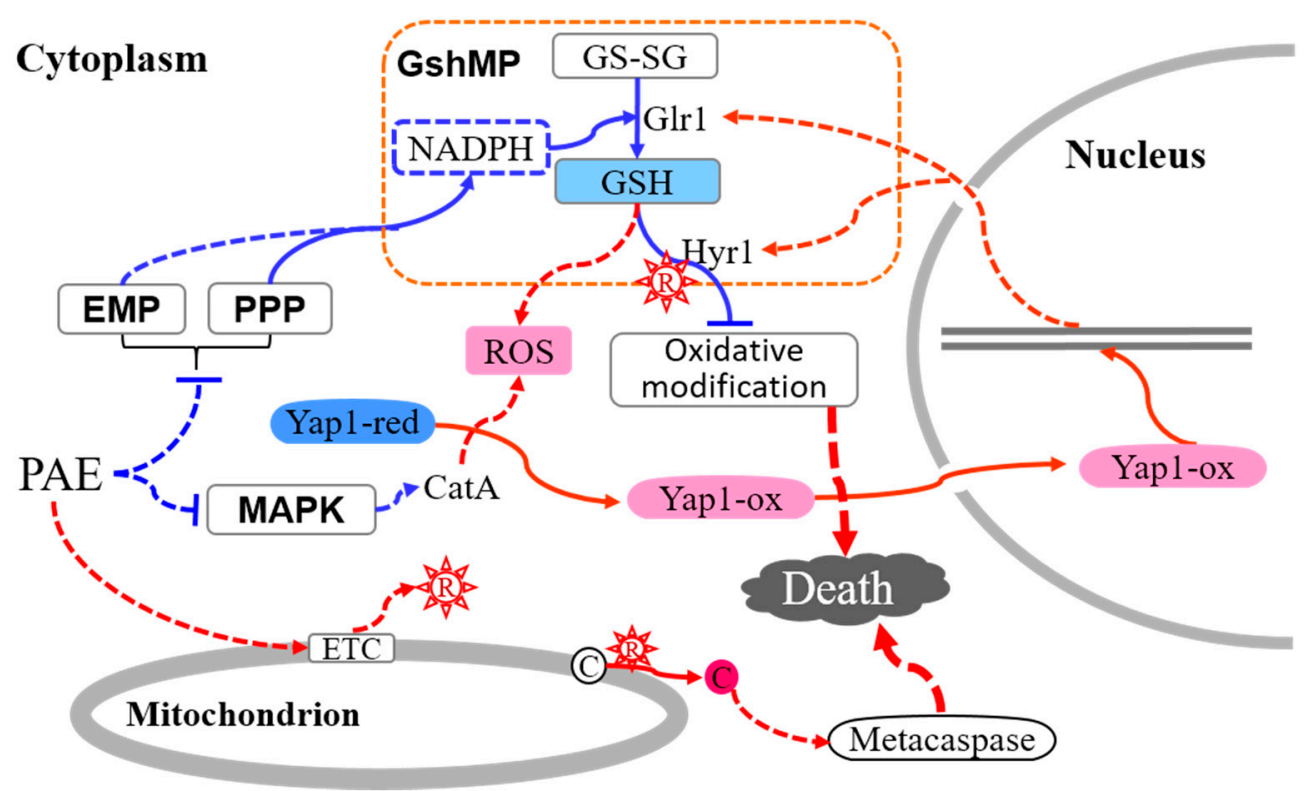

Figure 9. A schematic illustration of the potential mechanism that PAE induces cell death in A. flavus.

Author Contributions: Conceptualization, Y.-X.L.; software, C.P.; validation, Y.M., X.H., and Q.G.; writing-original draft preparation, C.P.; writing-review and editing, J.T and E.F.; visualization, K.Y.; project administration, M.L.; funding acquisition, J.T. All authors have read and agreed to the published version of the manuscript.

Funding: This research was funded by National Natural Science Foundation of China $(31972171,31671944$ and 31900036), Six Talent Peaks Project of Jiangsu Province (SWYY-026), Qing Lan Project of Jiangsu Province, Natural Science Foundation by Xuzhou City (KC17053), the Industry-University-Academy Prospective Joint Research Project of Jiangsu Province (BY2016028-01) and the PAPD of Jiangsu Higher Education Institutions.

Conflicts of Interest: The authors declare no conflicts of interest.

$\begin{array}{ll}\text { Abbreviations } & \\ \text { Cyt c } & \text { cytochrome c } \\ \text { DEGs } & \begin{array}{l}\text { differentially expressed genes } \\ \text { essential oils } \\ \text { EOs }\end{array} \\ \text { electron transport chain } \\ \text { fragments per kilobase of transcript per million } \\ \text { FPKM } & \text { fragments mapped } \\ \text { GO } & \text { Gene Ontology } \\ \text { GSH } & \text { glutathione } \\ \text { GshMP } & \text { GSH metabolism pathway } \\ \text { KEGG } & \text { Kyoto Encyclopedia of Genes and Genomes } \\ \text { MAPK } & \text { mitogen activated protein kinase } \\ \text { MDS } & \text { mitogen activated protein kinase } \\ \text { MDS } & \text { multidimensional scaling plot } \\ \text { NADPH } & \text { reduced nicotinamide adenine dinucleotide phosphate } \\ \text { NOXs } & \text { NADPH oxidases } \\ \text { PAE } & \text { perillaldehyde } \\ \text { PPP } & \text { pentose phosphate pathway } \\ \text { RT-qPCR } & \text { real-time qPCR } \\ \text { ROS } & \text { reactive oxygen species } \\ \text { Trx } & \text { thioredoxin }\end{array}$




\section{References}

1. Diener, U.L.; Cole, R.J.; Sanders, T.H.; Payne, G.A.; Lee, L.S.; Klich, M.A. Epidemiology of aflatoxin formation by Aspergillus flavus. Annu. Rev. Phytopathol. 1987, 25, 249-270. [CrossRef]

2. Klich, M.A. Aspergillus flavus: The major producer of aflatoxin. Mol. Plant Pathol. 2007, 8, 713-722. [CrossRef] [PubMed]

3. Lewis, L.; Onsongo, M.; Njapau, H.; Schurz-Rogers, H.; Luber, G.; Kieszak, S.; Nyamongo, J.; Backer, L.; Dahiye, A.M.; Misore, A.; et al. Aflatoxin contamination of commercial maize products during an outbreak of acute aflatoxicosis in eastern and central Kenya. Environ. Health Perspect. 2005, 113, 1763-1767. [CrossRef] [PubMed]

4. Amaike, S.; Keller, N.P. Aspergillus flavus. Annu. Rev. Phytopathol. 2011, 49, 107-133. [CrossRef]

5. Hobbs, C.A.; Taylor, S.V.; Beevers, C.; Lloyd, M.; Bowen, R.; Lillford, L.; Maronpot, R.; Hayashi, S.M. Genotoxicity assessment of the flavouring agent, perillaldehyde. Food Chem. Toxicol. 2016, 97, $232-242$. [CrossRef]

6. Sato, K.; Krist, S.; Buchbauer, G. Antimicrobial effect of trans-cinnamaldehyde, (-)-perillaldehyde, (-)-citronellal, citral, eugenol and carvacrol on airborne microbes using an airwasher. Biol. Pharm. Bull. 2006, 29, 2292-2294. [CrossRef]

7. Mcgeady, P.; Wansley, D.L.; Logan, D.A. Carvone and perillaldehyde interfere with the serum-induced formation of filamentous structures in Candida albicans at substantially lower concentrations than those causing significant inhibition of growth. J. Nat. Prod. 2002, 65, 953-955. [CrossRef]

8. Tian, J.; Zeng, X.; Lü, A.; Zhu, A.; Peng, X.; Wang, Y. Perillaldehyde, a potential preservative agent in foods: Assessment of antifungal activity against microbial spoilage of cherry tomatoes. LWT-Food Sci. Technol. 2015, 60, 63-70. [CrossRef]

9. Tian, J.; Wang, Y.; Zeng, H.; Li, Z.; Zhang, P.; Tessema, A.; Peng, X. Efficacy and possible mechanisms of perillaldehyde in control of Aspergillus niger causing grape decay. Int. J. Food Microbiol. 2015, 202, 27-34. [CrossRef]

10. Tian, J.; Wang, Y.; Lu, Z.; Sun, C.; Zhang, M.; Zhu, A.; Peng, X. Perillaldehyde, a promising antifungal agent used in food preservation, triggers apoptosis through a metacaspase-dependent pathway in Aspergillus flavus. J. Agric. Food Chem. 2016, 64, 7404-7413. [CrossRef]

11. Kagan, V.E.; Tyurin, V.A.; Jiang, J.F.; Tyurina, Y.Y.; Ritov, V.B.; Amoscato, A.A.; Osipov, A.N.; Belikova, N.A.; Kapralov, A.A.; Kini, V.; et al. Cytochrome c acts as a cardiolipin oxygenase required for release of proapoptotic factors. Nat. Chem. Biol. 2005, 1, 223-232. [CrossRef] [PubMed]

12. Pedrajas, J.R.; Miranda-Vizuete, A.; Javanmardy, N.; Gustafsson, J.A.; Spyrou, G. Mitochondria of Saccharomyces cerevisiae contain one-conserved cysteine type peroxiredoxin with thioredoxin peroxidase activity. J. Biol. Chem. 2000, 275, 16296-16301. [CrossRef]

13. Circu, M.L.; Aw, T.Y. Glutathione and apoptosis. Free Radic. Res. Commun. 2008, 42, 689-706. [CrossRef] [PubMed]

14. Collet, J.F.; D'Souza, J.C.; Jakob, U.; Bardwell, J.C. Thioredoxin 2, an oxidative stress-induced protein, contains a high affinity zinc binding site. J. Biol. Chem. 2003, 278, 45325-45332. [CrossRef]

15. Larochelle, M.; Drouin, S.; Robert, F.; Turcotte, B. Oxidative stress-activated zinc cluster protein Stb5 has dual activator/repressor functions required for pentose phosphate pathway regulation and NADPH production. Mol. Cell Biol. 2006, 26, 6690-6701. [CrossRef] [PubMed]

16. Shi, F.; Kawai, S.; Mori, S.; Kono, E.; Murata, K. Identification of ATP-NADH kinase isozymes and their contribution to supply of NADP(H) in Saccharomyces cerevisiae. FEBS J. 2005, 272, 3337-3349. [CrossRef] [PubMed]

17. Stanley, B.A.; Sivakumaran, V.; Shi, S.; McDonald, I.; Lloyd, D.; Watson, W.H.; Aon, M.A.; Paolocci, N. Thioredoxin reductase-2 is essential for keeping low levels of $\mathrm{H}_{2} \mathrm{O}_{2}$ emission from isolated heart mitochondria. J. Biol. Chem. 2011, 286, 33669-33677. [CrossRef]

18. Maiorino, M.; Ursini, F.; Bosello, V.; Toppo, S.; Tosatto, S.C.; Mauri, P.; Becker, K.; Roveri, A.; Bulato, C.; Benazzi, L.; et al. The thioredoxin specificity of Drosophila GPx: A paradigm for a peroxiredoxin-like mechanism of many glutathione peroxidases. J. Mol. Biol. 2007, 365, 1033-1046. [CrossRef]

19. Collinson, E.J.; Wheeler, G.L.; Garrido, E.O.; Avery, A.M.; Avery, S.V.; Grant, C.M. The yeast glutaredoxins are active as glutathione peroxidases. J. Biol. Chem. 2002, 277, 16712-16717. [CrossRef] 
20. Kanehisa, M.; Goto, S.; Kawashima, S.; Okuno, Y.; Hattori, M. The KEGG resource for deciphering the genome. Nucleic Acids Res. 2004, 32, D277-D280. [CrossRef]

21. Outten, C.E.; Culotta, V.C. Alternative start sites in the Saccharomyces cerevisiae GLR1 gene are responsible for mitochondrial and cytosolic isoforms of glutathione reductase. J. Biol. Chem. 2004, 279, 7785-7791. [CrossRef] [PubMed]

22. Tsuzi, D.; Maeta, K.; Takatsume, Y.; Izawa, S.; Inoue, Y. Regulation of the yeast phospholipid hydroperoxide glutathione peroxidase GPX2 by oxidative stress is mediated by Yap1 and Skn7. FEBS Lett. 2004, 565, 148-154. [CrossRef] [PubMed]

23. Grant, C.M.; Collinson, L.P.; Roe, J.H.; Dawes, I.W. Yeast glutathione reductase is required for protection against oxidative stress and is a target gene for yAP-1 transcriptional regulation. Mol. Microbiol. 1996, 21, 171-179. [CrossRef] [PubMed]

24. Latimer, H.R.; Veal, E.A. Peroxiredoxins in regulation of MAPK signalling pathways; sensors and barriers to signal transduction. Mol. Cells 2016, 39, 40-45.

25. Lee, J.; Godon, C.; Lagniel, G.; Spector, D.; Garin, J.; Labarre, J.; Toledano, M.B. Yap1 and Skn7 control two specialized oxidative stress response regulons in yeast. J. Biol. Chem. 1999, 274, 16040-16046. [CrossRef]

26. Rodriguez-Rodriguez, P.; Fernandez, E.; Almeida, A.; Bolanos, J.P. Excitotoxic stimulus stabilizes PFKFB3 causing pentose-phosphate pathway to glycolysis switch and neurodegeneration. Cell Death. Differ. 2012, 19, 1582-1589. [CrossRef]

27. Patra, K.C.; Hay, N. The pentose phosphate pathway and cancer. Trends Biochem. Sci. 2014, 39, 347-354. [CrossRef]

28. Fraser, J.A.; Davis, M.A.; Hynes, M.J. A gene from Aspergillus nidulans with similarity to URE2 of Saccharomyces cerevisiae encodes a glutathione S-transferase which contributes to heavy metal and xenobiotic resistance. Appl. Environ. Microbiol. 2002, 68, 2802-2808. [CrossRef]

29. Lee, Y.D.; Wang, J.; Stubbe, J.; Elledge, S.J. Dif1 is a DNA-damage-regulated facilitator of nuclear import for ribonucleotide reductase. Mol. Cell 2008, 32, 70-80. [CrossRef]

30. Klionsky, D.J.; Emr, S.D. Autophagy as a regulated pathway of cellular degradation. Science 2000, 290, 1717-1721. [CrossRef]

31. Kabeya, Y.; Kamada, Y.; Baba, M.; Takikawa, H.; Sasaki, M.; Ohsumi, Y. Atg17 functions in cooperation with Atg1 and Atg13 in yeast autophagy. Mol. Biol. Cell 2005, 16, 2544-2553. [CrossRef] [PubMed]

32. Perry, D.K.; Carton, J.; Shah, A.K.; Meredith, F.; Uhlinger, D.J.; Hannun, Y.A. Serine palmitoyltransferase regulates de novoceramide generation during etoposide-induced apoptosis. J. Biol. Chem. 2000, 275, 9078-9084. [CrossRef] [PubMed]

33. Mizushima, N.; Levine, B.; Cuervo, A.M.; Klionsky, D.J. Autophagy fights disease through cellular self-digestion. Nature 2008, 451, 1069-1075. [CrossRef] [PubMed]

34. De Vries, R.P.; Flitter, S.J.; Van De Vondervoort, P.J.; Chaveroche, M.K.; Fontaine, T.; Fillinger, S.; Ruijter, G.J.; D’Enfert, C.; Visser, J. Glycerol dehydrogenase, encoded by gldB is essential for osmotolerance in Aspergillus nidulans. Mol. Microbiol. 2003, 49, 131-141. [CrossRef]

35. Caceres, I.; El Khoury, R.; Bailly, S.; Oswald, I.P.; Puel, O.; Bailly, J.D. Piperine inhibits aflatoxin B1 production in Aspergillus flavus by modulating fungal oxidative stress response. Fungal Genet. Biol. 2017, 107, 77-85. [CrossRef]

36. Boyce, K.J.; Cao, C.; Andrianopoulos, A. Two-component signaling regulates osmotic stress adaptation via SskA and the high-osmolarity glycerol MAPK pathway in the human pathogen talaromyces marneffei. MSphere 2016, 1, e00086-15. [CrossRef]

37. Balázs, A.; Pócsi, I.; Hamari, Z.; Leiter, É.; Emri, T.; Miskei, M.; Oláh, J.; Tóth, V.; Hegedús, N.; Prade, R.A. AtfA bZIP-type transcription factor regulates oxidative and osmotic stress responses in Aspergillus nidulans. Mol. Genet. Genom. 2010, 283, 289-303. [CrossRef]

38. Ren, S.; Yang, M.; Li, Y.; Zhang, F.; Chen, Z.; Zhang, J.; Yang, G.; Yue, Y.; Li, S.; Ge, F.; et al. Global phosphoproteomic analysis reveals the involvement of phosphorylation in aflatoxins biosynthesis in the pathogenic fungus Aspergillus flavus. Sci. Rep. 2016, 6, 34078. [CrossRef]

39. Alves de Castro, P.; dos Reis, T.F.; Dolan, S.K.; Oliveira Manfiolli, A.; Brown, N.A.; Jones, G.W.; Doyle, S.; Riaño-Pachón, D.M.; Squina, F.M.; Caldana, C. The Aspergillus fumigatus SchASCH9 kinase modulates SakAHOG1 MAP kinase activity and it is essential for virulence. Mol. Microbiol. 2016, 102, 642-671. [CrossRef] 
40. Pramila, T.; Miles, S.; GuhaThakurta, D.; Jemiolo, D.; Breeden, L.L. Conserved homeodomain proteins interact with MADS box protein Mcm1 to restrict ECB-dependent transcription to the M/G1 phase of the cell cycle. Genes Dev. 2002, 16, 3034-3045. [CrossRef]

41. Banerjee, N.; Zhang, M.Q. Identifying cooperativity among transcription factors controlling the cell cycle in yeast. Nucleic Acids Res. 2003, 31, 7024-7031. [CrossRef] [PubMed]

42. Omari-Siaw, E.; Zhu, Y.; Wang, H.; Peng, W.; Firempong, C.K.; Wang, Y.W.; Cao, X.; Deng, W.; Yu, J.; Xu, X. Hypolipidemic potential of perillaldehyde-loaded self-nanoemulsifying delivery system in high-fat diet induced hyperlipidemic mice: Formulation, in vitro and in vivo evaluation. Eur. J. Pharm. Sci. 2016, 85, 112-122. [CrossRef] [PubMed]

43. Uemura, T.; Yashiro, T.; Oda, R.; Shioya, N.; Nakajima, T.; Hachisu, M.; Kobayashi, S.; Nishiyama, C.; Arimura, G.I. Intestinal anti-inflammatory activity of perillaldehyde. J. Agric. Food. Chem. 2018, 66, 3443-3448. [CrossRef] [PubMed]

44. Qu, S.; Chen, L.; Tian, H.; Wang, Z.; Wang, F.; Wang, L.; Li, J.; Ji, H.; Xi, L.; Feng, Z.; et al. Effect of perillaldehyde on prophylaxis and treatment of vaginal candidiasis in a murine model. Front. Microbiol. 2019, 10, 1466. [CrossRef]

45. Ito, N.; Nagai, T.; Oikawa, T.; Yamada, H.; Hanawa, T. Antidepressant-like effect of l-perillaldehyde in stress-induced depression-like model mice through regulation of the olfactory nervous system. Evid. Based Complement. Altern. Med. 2011, 2011, 1-5. [CrossRef] [PubMed]

46. Tian, J.; Pan, C.; Zhang, M.; Gan, Y.; Pan, S.; Liu, M.; Li, Y.; Zeng, X. Induced cell death in Ceratocystis fimbriata by pro-apoptotic activity of a natural organic compound, perillaldehyde, through $\mathrm{Ca}^{2+}$ overload and accumulation of reactive oxygen species. Plant Pathol. 2019, 68, 344-357. [CrossRef]

47. Tian, H.; Qu, S.; Wang, Y.; Lu, Z.; Zhang, M.; Gan, Y.; Zhang, P.; Tian, J. Calcium and oxidative stress mediate perillaldehyde-induced apoptosis in Candida albicans. Appl. Microbiol. Biotechnol. 2017, 101, 3335-3345. [CrossRef]

48. Knobloch, K.; Pauli, A.; Iberl, B.; Weigand, H.; Weis, N. Antibacterial and antifungal properties of essential oil components. J. Essent. Oil Res. 1989, 1, 119-128. [CrossRef]

49. Wang, Y.; Zeng, X.; Zhou, Z.; Xing, K.; Tessema, A.; Zeng, H.; Tian, J. Inhibitory effect of nerol against Aspergillus niger on grapes through a membrane lesion mechanism. Food Control 2015, 55, 54-61. [CrossRef]

50. Cha, M.K.; Kim, H.K.; Kim, I.H. Thioredoxin-linked "thiol peroxidase" from periplasmic space of Escherichia coli. J. Biol. Chem. 1995, 270, 28635-28641. [CrossRef]

51. Bakkali, F.; Averbeck, S.; Averbeck, D.; Idaomar, M. Biological effects of essential oils-A review. Food Chem. Toxicol. 2008, 46, 446-475. [CrossRef] [PubMed]

52. Murphy, M.P. How mitochondria produce reactive oxygen species. Biochem. J. 2009, 417, 1-13. [CrossRef] [PubMed]

53. Valko, M.; Morris, H.; Cronin, M.T. Metals, toxicity and oxidative stress. Curr. Med. Chem. 2005, 12, 1161-1208. [CrossRef] [PubMed]

54. Reczek, C.R.; Chandel, N.S. ROS-dependent signal transduction. Curr. Opin. Cell Biol. 2015, 33, 8-13. [CrossRef]

55. Toledano, M.B.; Kumar, C.; Le Moan, N.; Spector, D.; Tacnet, F. The system biology of thiol redox system in Escherichia coli and yeast: Differential functions in oxidative stress, iron metabolism and DNA synthesis. FEBS Lett. 2007, 581, 3598-3607. [CrossRef]

56. Le, M.N.; Clement, G.; Le, M.S.; Tacnet, F.; Toledano, M.B. The Saccharomyces cerevisiae proteome of oxidized protein thiols: Contrasted functions for the thioredoxin and glutathione pathways. J. Biol. Chem. 2006, 281, 10420-10430.

57. Bauer, H.; Kanzok, S.M.; Schirmer, R.H. Thioredoxin-2 but not thioredoxin-1 is a substrate of thioredoxin peroxidase-1 from Drosophila melanogaster: Isolation and characterization of a second thioredoxin in D. Melanogaster and evidence for distinct biological functions of Trx-1 and Trx-2. J. Biol. Chem. 2002, 277, 17457-17463. [CrossRef]

58. Caccuri, A.M.; Antonini, G.; Allocati, N.; Di Ilio, C.; De Maria, F.; Innocenti, F.; Parker, M.W.; Masulli, M.; Lo Bello, M.; Turella, P.; et al. GSTB1-1 from Proteus mirabilis: A snapshot of an enzyme in the evolutionary pathway from a redox enzyme to a conjugating enzyme. J. Biol. Chem. 2002, 277, 18777-18784. [CrossRef] 
59. Golla, U.; Singh, V.; Azad, G.K.; Singh, P.; Verma, N.; Mandal, P.; Chauhan, S.; Tomar, R.S. Sen1p contributes to genomic integrity by regulating expression of ribonucleotide reductase 1 (RNR1) in Saccharomyces cerevisiae. PLoS ONE 2013, 8, e64798. [CrossRef]

60. Rodriguez, A.; de la Cera, T.; Herrero, P.; Moreno, F. The hexokinase 2 protein regulates the expression of the GLK1, HXK1 and HXK2 genes of Saccharomyces cerevisiae. Biochem. J. 2001, 355, 625-631. [CrossRef]

61. Reeves, R.E.; Serrano, R.; South, D.J. 6-phosphofructokinase (pyrophosphate). Properties of the enzyme from Entamoeba histolytica and its reaction mechanism. J. Biol. Chem. 1976, 251, 2958-2962. [PubMed]

62. Outten, C.E.; Culotta, V.C. A novel NADH kinase is the mitochondrial source of NADPH in Saccharomyces cerevisiae. EMBO J. 2014, 22, 2015-2024. [CrossRef] [PubMed]

63. Izawa, S.; Inoue, Y.; Kimura, A. Importance of catalase in the adaptive response to hydrogen peroxide: Analysis of acatalasaemic Saccharomyces cerevisiae. Biochem. J. 1996, 320, 61-67. [CrossRef]

64. Raspelli, E.; Facchinetti, S.; Fraschini, R. Swe1 and Mih1 regulate mitotic spindle dynamics in budding yeast via Bik1. J. Cell Sci. 2018, 131. [CrossRef] [PubMed]

65. Nierman, W.C.; Yu, J.; Fedorova-Abrams, N.D.; Losada, L.; Cleveland, T.E.; Bhatnagar, D.; Bennett, J.W.; Dean, R.; Payne, G.A. Genome sequence of Aspergillus flavus NRRL 3357, a strain that causes aflatoxin contamination of food and feed. Genome Announc. 2015, 3, e00168-15. [CrossRef]

66. Dhar, R.; Sagesser, R.; Weikert, C.; Wagner, A. Yeast adapts to a changing stressful environment by evolving cross-protection and anticipatory gene regulation. Mol. Biol. Evol. 2013, 30, 573-588. [CrossRef]

67. Kim, D.; Pertea, G.; Trapnell, C.; Pimentel, H.; Kelley, R.; Salzberg, S.L. TopHat2: Accurate alignment of transcriptomes in the presence of insertions, deletions and gene fusions. Genome Biol. 2013, 14, R36. [CrossRef]

68. Florea, L.; Song, L.; Salzberg, S.L. Thousands of exon skipping events differentiate among splicing patterns in sixteen human tissues. F1000Research 2013, 2, 188. [CrossRef]

69. Ritchie, M.E.; Phipson, B.; Wu, D.; Hu, Y.; Law, C.W.; Shi, W.; Smyth, G.K. limma powers differential expression analyses for RNA-sequencing and microarray studies. Nucleic Acids Res. 2015, 43, e47. [CrossRef]

70. Warnes, G.R.; Bolker, B.; Bonebakker, L.; Gentleman, R.; Liaw, W.H.A.; Lumley, T.; Maechler, M.; Magnusson, A.; Moeller, S.; Schwartz, M. Gplots: Various R Programming Tools for Plotting Data. R package version 3.0. 1. Compr. R Arch. Netw. 2016. Available online: https://rdrr.io/cran/gplots/ (accessed on 11 January 2020).

71. Yu, G.; Wang, L.G.; Han, Y.; He, Q.Y. clusterProfiler: An R package for comparing biological themes among gene clusters. OMICS 2012, 16, 284-287. [CrossRef]

72. Szklarczyk, D.; Gable, A.L.; Lyon, D.; Junge, A.; Wyder, S.; Huerta-Cepas, J.; Simonovic, M.; Doncheva, N.T.; Morris, J.H.; Bork, P.; et al. STRING v11: Protein-protein association networks with increased coverage, supporting functional discovery in genome-wide experimental datasets. Nucleic Acids Res. 2019, 47, D607-D613. [CrossRef] [PubMed]

73. Seip, E.R.; Woloshuk, C.P.; Payne, G.A.; Curtis, S.E. Isolation and sequence analysis of a beta-tubulin gene from Aspergillus flavus and its use as a selectable marker. Appl. Environ. Microbiol. 1990, 56, 3686-3692. [CrossRef] [PubMed]

74. Livak, K.J.; Schmittgen, T.D. Analysis of relative gene expression data using real-time quantitative PCR and the 2(-Delta Delta C(T)) Method. Methods 2001, 25, 402-408. [CrossRef] [PubMed]

(C) 2020 by the authors. Licensee MDPI, Basel, Switzerland. This article is an open access article distributed under the terms and conditions of the Creative Commons Attribution (CC BY) license (http://creativecommons.org/licenses/by/4.0/). 